\title{
47 \\ The practical limits for J.I.T.
}

Prof. Dr. Javier Borda Elejabarrieta

C.E.O. of Datalde Sisteplant, S.A., Professor of Production and Engineering. Management Deusto University, Member of I.F.I.P. WG 5.7.

Parque Tecnológico Edificio 10548170 ZAMUDIO Spain

Phone: (34) 44520611 Fax. (34) 44521266

E-mail: datalde@redestb.es

\begin{abstract}
Zero Inventories (Z.I.) or near zero inventories, are we doing the right thing? Some years ago going along with inventory reduction beyond the more or less apparent economic optimal level has been justified in terms of getting the synergistic effects of flexibility, productivity and quality, and we all have seen the very famous diagram representing a company as a ship crashing into reefs when low tide (low inventories) comes.

That is really true, and till a certain limit, clear savings in expenses are obtained from this policy simply doing things right with no significative investment. Therefore, you normally are forced to reduce lead-times, with synergistics effects. This is a path to be walked at a fastpace, at what point do we stop ? The paper establishes the practical limits for inventory reduction using the concept of the "economic transfer lot" that is affected, among other factors, by the practical economic level of the "minimum production lot", that is calculated in terms of the "manufacturing system decision triangle"
\end{abstract}

Keywords 


\section{INTRODUCTION}

Car component makers are particularly forced to make continuous improvements in lead-times and costs reduction. Figure 1 represents a very attractive interaction in which cleverly focused lead-time reduction leads to dramatically reduced costs simultaneously improving quality and service. But is this an absolute linear nonending model, suggesting Z.I. (Zero Inventories) as the panacea for best manufacturing practices. The answer is no. The multiplying links of the figure works out only from an initial manufacturing system given situation to another in which the maximum limit achievable manufacturing flexibility is a function of the involved machines technology.

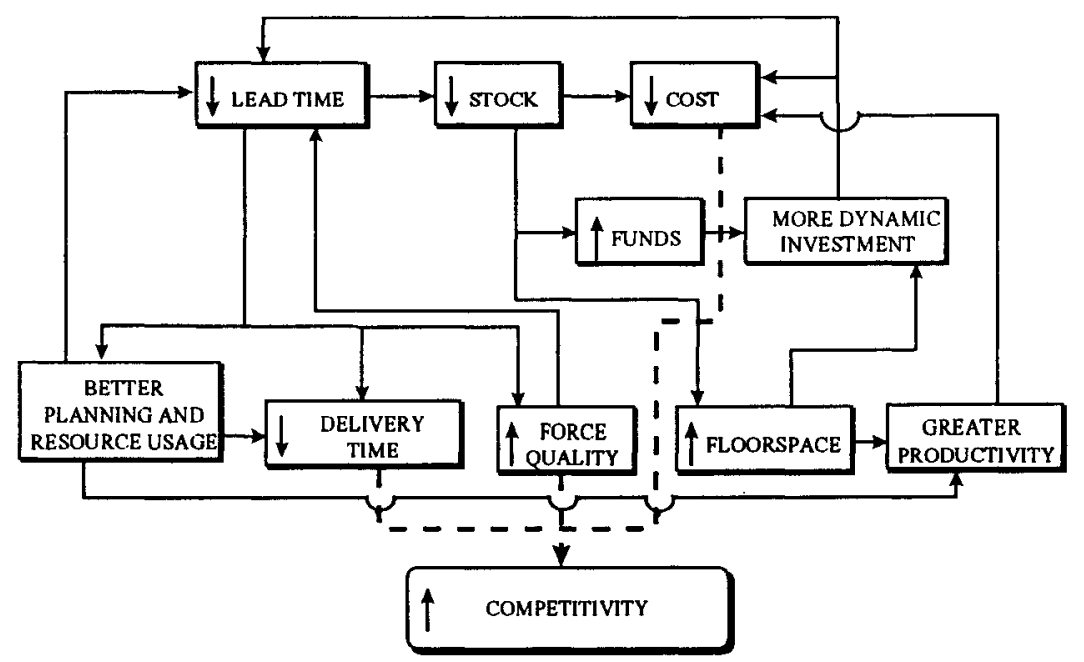

FIG. 1: LEAD TIME, ITS REDUCTION AND COMPETIVITY IMPROVEMENT Note the "multiplying" characteristics of the links.

Going onreducing set-up times beyond this point is just a waste of precious time and money. Therefore, the minimum level of inventory you can have depends only on the Technology Strategy you are practicing. The confusion stands because the problem in real life is identification of the inventory sources. Taking that into account if you reduce the level of the inventory related to a lot-sizing practice of (roughly $1 / 2 \mathrm{EOQ}$ ), and you compare the figure with plant obtained samples, the surprise is that theoretical inventory is only one third (or less) than the sampled. Where is the difference? Very easy; on things that must be dramatically eradicated; machine breakdowns, inadequate and suppressive CPK's, scrap and rework, under controlled process adjustments of setting up with loss of expensive material, or inadequate or very slow operating planning and scheduling systems. Z.I. that must be pursued most is the inventory you have because all these things more or less randomly occur. This is the limit of linear behaviour of the model showed in Figure 1, and what we call P.Z.I. (practical zero inventories). 
Proper identification and removal of these scraps requires the previous setting of logistics model and a coupled technology strategy for the involved machines and plant physical systems.

\section{THE LOGISTIC MODEL AND THE MANUFACTURING DECISION TRIANGLE}

Supposed defined if you are an assemble to order (ATO), manufacturing to order (MTO) or a manufacturing to stock (MTS), the identification of main and auxiliary lines is the key $o$ issue. The Figure 2 represents the layout of lines.

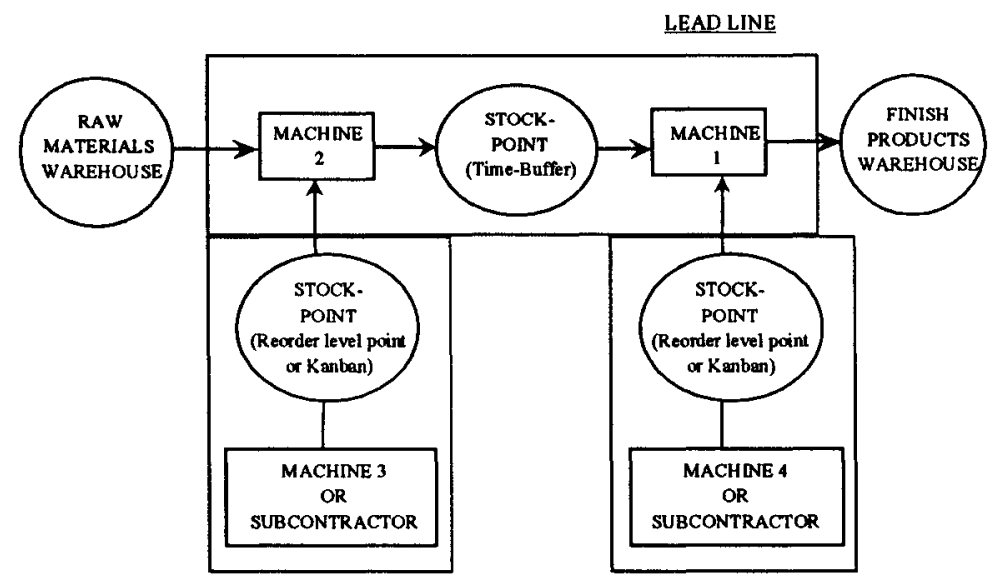

FIO. 2. LEAD AND AUXILIARY LINES. A SIMPLE MODEL

The main line is synchronized, as a time buffered inventory, contains the most value added product parts and process technology, and sets the manufacturing lead-times. The main lines contains the reserve capacity for differentiation of product inventory, quality, flexibility and service, and cost reduction for the future. The auxiliary lines (machines or subcontractors) are decoupled systems likely producing any of the rest of the areas represented in Figure 3, and performing JT or reorder-level-point operating practices. 


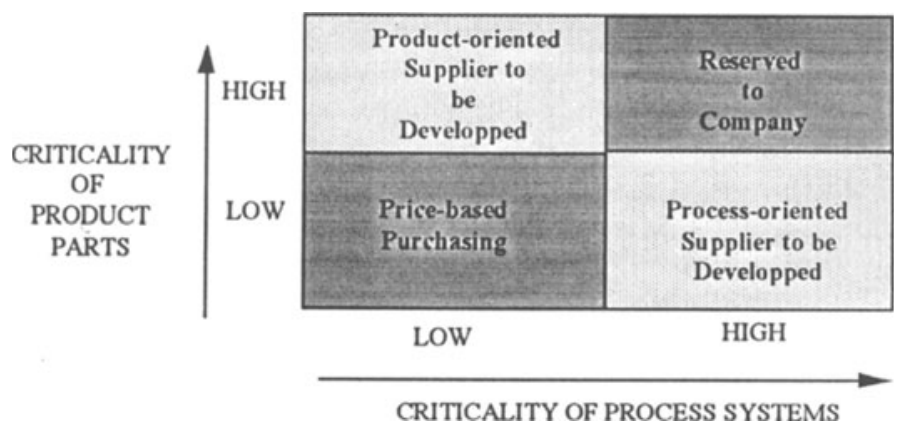

FIG. 3. THE ADDED-VALUE MATRIX

Main lines are the places to perform PZI, and doing this hierarchically through the logistic model is extremely useful, given that it channels product and process innovation and more intensive continuous improvement management efforts.

Which is the most convenient practical lot-size in the main-line? If you can manufacture as small as you rationally can move, you get the following:

- If the customer is fixed orders window is small (and in fact is decreasing continuously), there is a clear trend to order what is reasonable to move and deliver in manufacturing lots equal the main line remains syncronized along process stages.

- Operative integration of production and material handling personnel with decreasing labour costs through polivalence and self-balancing.

- Extremely simple and straight planning, scheduling and control systems, complemented by easy work in progress visual traceability.

- Everything in the plant must be moving (with exception of safety time-bufferstock) and assigned to a customer order.

- Safety time-buffer stock size, convenience and lead-time added is clearly and continuously visually identified so decisions about definitive or occasional removal of safety are very easy to take.

- With the exception of some given scheduling conveniences (grouping for savings in set-up times), customer orders priorities or changes have reduced productivity.

So, it is clear that in the main line manufacturing technology must be coupled with the idea of doing manufacturing lot size equal to transfer lot size. The level of the transfer lot-size is selected with the criteria of minimizing handling costs, and depends on the product morphology, distances, and transport device design (selected for minimum handling costs).

With these conditions, we have to select the manufacturing technology for the main line. Minimum theoretical set-up times have to be reasonable for producing 
transfer lot sizes, and are calculated reversing the well known "Wilson" or "Coverage" formula (Coverage analysis is more appropriated for a family of products produced in expensive main lines). With deduced convenient set-up times, maximum admitted direct and labour costs, and product life cycle, we move to the Figure 4; the machine decision triangle.

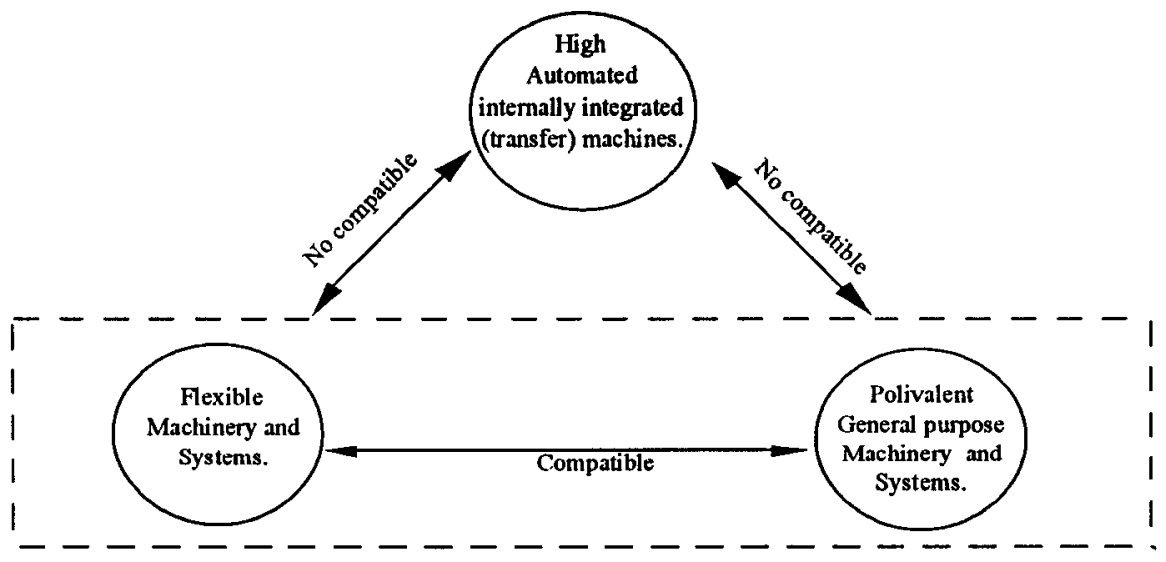

FIG. 4. MANUFACTURING SYSTEM DECISION TRIANGLE

Looking at the figure, and if needed flexibility is given by the transfer-lot, what we have to do is move as much as possible to automation but keeping the ability for rapidity in changeovers. This contradictory trade-off can be alter in own favour with good integrated product and process engineering practices. The Table 1 represents how to decide on the different alternatives, and Figure 5 situates them on an interline flow-chart. 


\section{TABLE 1}

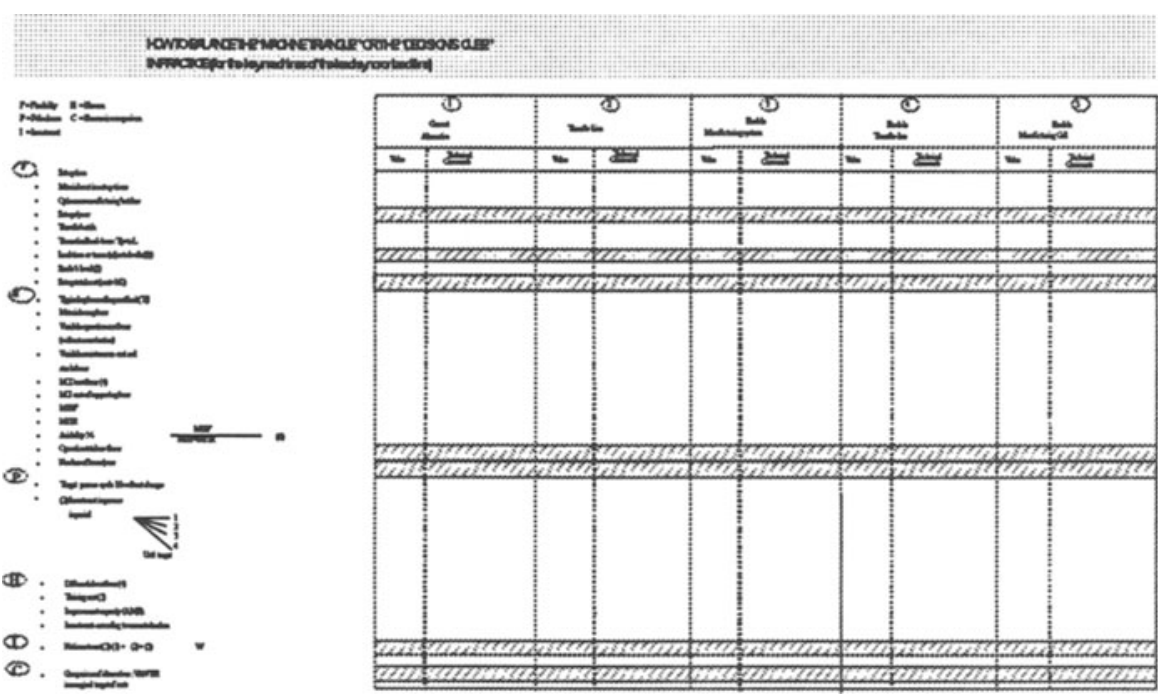



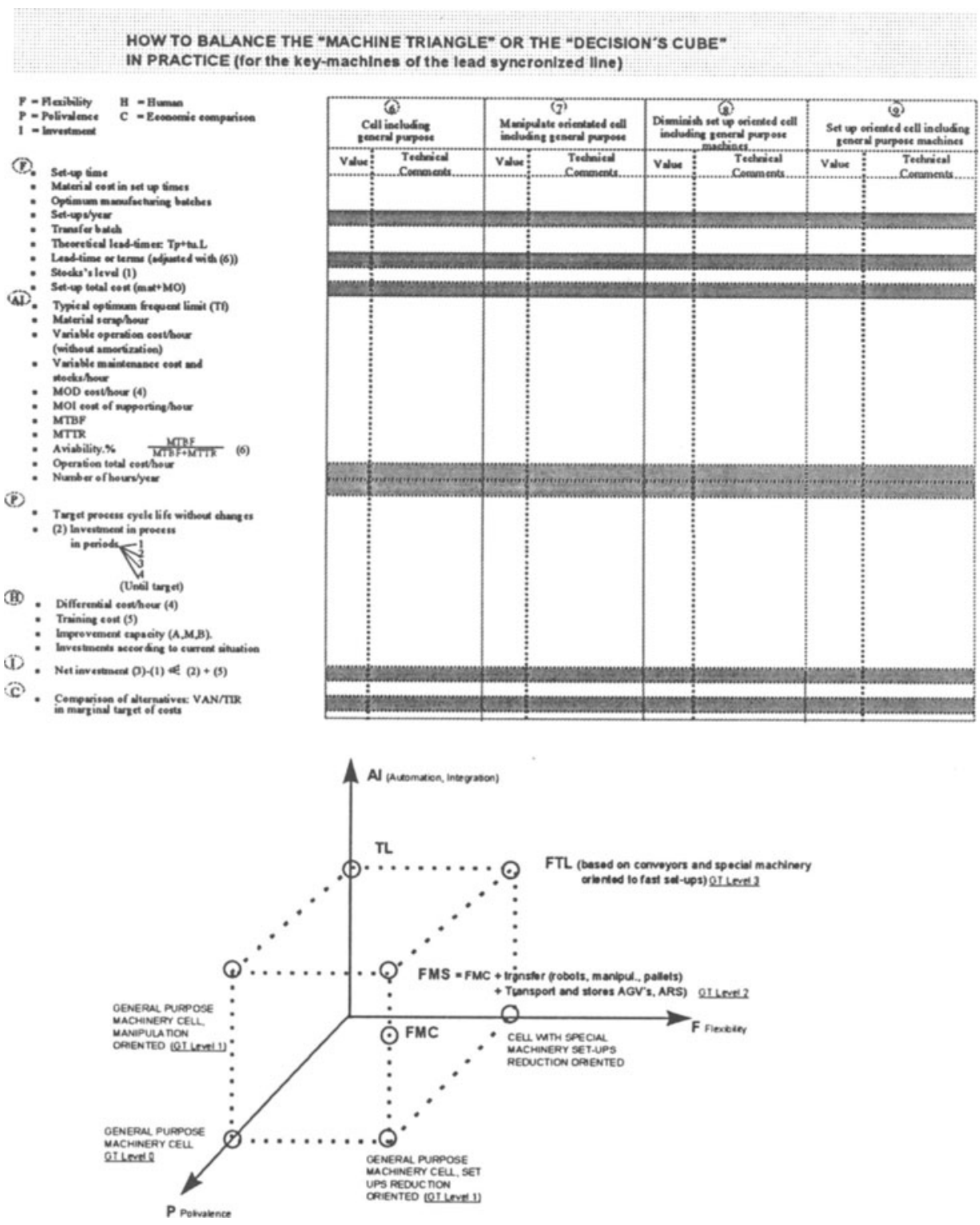

FIG. 5. THE DECISION CUBE

$\mathrm{TL}=$ transfer-line

FTL = flexible transfer - line

FMS = flexible manufacturing system

$\mathrm{FMC}=$ flexible manufacturing cell 


\section{DEDUCTION OF PZI AND RELATED M.I.S (management information system)}

The size of PZI can be calculated in a roughly way (formula-based) or by simulation of optimal sequences in scheduling systems software that has the input of the MPS (master-plan) for the main-line (FIG. 6). The difference is that in the first, products are independently pipe-lined along the main line, and that with simulation grouping and changeover savings-and then some finish product inventory excess-arises. Depending on real cases, both are valid tactics, and their results are the ideal limits for plant management performance indicators.

The formula for deducting PZI for one part in terms of time is:
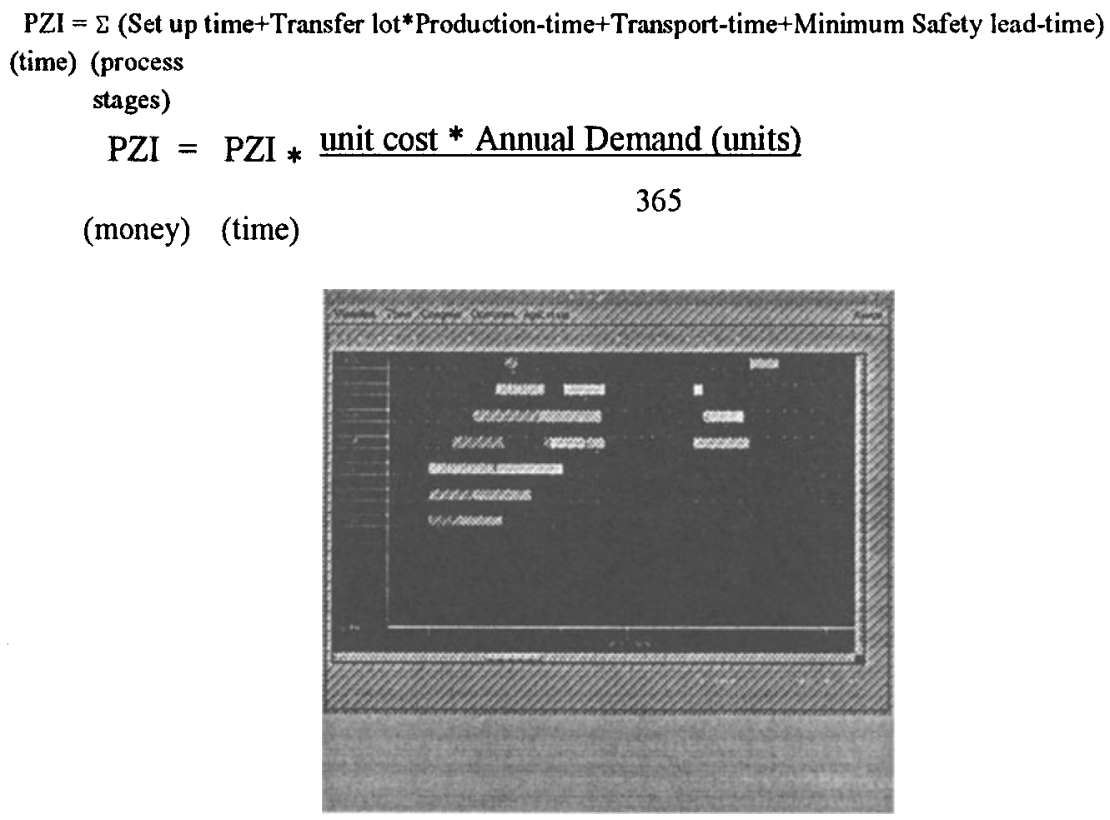

FIG. 6. GANTT CHART OF AN SCHEDULING SYSTEM SOFTWARE

Finally, a convenient M.I.S. for managing ZPI could be as follows:

- PZI excess (see FIG. 7) =

+๑ Time EDI - Time dispatching.

+ Time breakdowns and shortages - Time scheduled for buffering.

+ Time scraptrework - Time scheduled for buffering.

$+\bullet$ Non-identified . 
This non-identified piece of excess must also be continuously traced for deducting not so obvious problems.

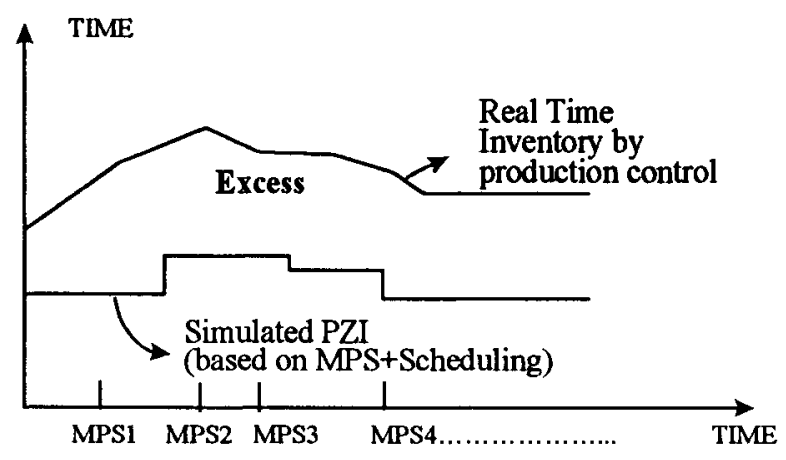

FIG. 7: INVENTORY EXCESS FROM PZI

\section{CONCLUSIONS}

The paper concludes saying that Z.I. is not, general speaking, a consistent strategy, but very interesting approach is arised if you fight Z.I. only for these all elements that are not part of the manufacturing system decision triangle strategy, and that push to you to have, sometimes, much more inventory than optimized correspondent set-up times EOQ would.

\section{BIOGRAPHY}

Prof. Dr. Javier Borda Elejabarrieta has been working as plant Engineer and Production Manager staff for 7 years, and from 1984 he is the managing director and C.E.O. of DATALDE, S.A., a spanish 35 people industrial engineering company, sited in the Basque Country. He read in 1989 the Doctoral Mechanical Engineering dissertation on "CIM for plastic injection workshops". He is also Professor of Production and Engineering Management in the University of Deusto, Bilbao, and the author of several international papers and a book titled: "Advanced Maintenance Techniques" (1990). He has become recently an IFIP WG 5.7 member.

\section{REFERENCES}

- (1987) (Dow Jones Irwin). "Zero Inventories", pp. 450 HALL .

- (1993) (R.E. Dauch) "Passion for Manufacturing" SME.

- (1988) (Th. J. Drozda) "Flexible Manufacturing Systems" SME.

- (1996) (Borda J.) "MRP-3 Concurrent integration of planning and scheduling in OKP". IFIP International Congress Kyoto-Japan. 
- (1997) (Borda J.) "How to do in high competitive surpresive markets"MATADOR CONGRESS- UMIST

- (1997) (Borda J.) "An extended coverage analysis for lot sizing group technology cells production environment"- ITAMS'91 CHINA (ELSEVIER) 